\title{
Multiculturalismo y derechos fundamentales en el noroeste de México: El caso de la tribu yaqui
}

\author{
Multiculturalism and fundamental rights in \\ Northwestern Mexico: The case of the Yaqui Tribe
}

Enrique F. Pasillas a* (D) (https://orcid.org/0000-0002-7183-4665)

${ }^{a}$ Universidad de Granada, Facultad de Derecho, Instituto de la Paz y los Conflictos, Granada, España, correo electrónico: efpasillas@correo.ugr.es

\section{Resumen:}

El objetivo del presente artículo es proponer una discusión sobre el papel de la multiculturalidad y sus implicaciones dentro del Estado nación mexicano desde la metodología del Derecho, dada la carencia de las herramientas jurídicas e institucionales para encausar el creciente reto de una sociedad multiétnica que aspira a una convivencia pacífica; donde los pueblos indígenas de México sostienen viejas demandas sobre el cumplimiento y respeto de sus derechos fundamentales, sustentadas ahora en el derecho y en la juris-

Recibido el 18 de mayo de 2017. Aceptado el 21 de febrero de 2018. Publicado el 4 de abril de 2018.

${ }^{*}$ Autor para correspondencia: Enrique F. Pasillas, correo electrónico: efpasillas@correo. ugr.es

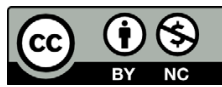

Esta obra está protegida bajo una Licencia Creative Commons Atribución-NoComercial 4.0 Internacional. prudencia internacionales. El análisis propuesto arroja que a pesar de las reformas constitucionales de 2001 y de 2011, es necesario ajustar el marco jurídico interno, introducir el pluralismo jurídico y la interculturalidad en la agenda pública y el espacio institucional. El caso de la tribu yaqui es paradigmático porque enarbola una lucha legal y pacífica por sus derechos fundamentales contra el despojo de sus territorios ancestrales y sus recursos naturales.

Palabras clave: multiculturalismo, derechos fundamentales, tribu yaqui.

\section{Abstract:}

The objective of this article is to propose a discussion on the role of multiculturalism and its implications within the Mexican nation-state from the methodology of legal studies, given the lack of legal and institutional tools to address the growing challenge of a multi ethnic society that aspires to a peaceful coexistence; where the indigenous peoples of Mexico uphold old demands on compliance with and respect for their Fundamental Rights, now based on international law and jurisprudence. The proposed analysis shows that despite the constitutional reforms of 2001 and 2011, it is necessary to introduce major legal reforms, including pluralism and interculturality in the public agenda and institutional space. The case of the Yaqui tribe is paradig-

CÓMO CITAR: Pasillas, E. F. (2018). Multiculturalismo y derechos fundamentales en el noroeste de México: El caso de la tribu yaqui [Multiculturalism and fundamental rights in Northwestern Mexico: The case of the Yaqui Tribe]. Estudios Fronterizos, 19 , e008. https://doi.org/10.21670/ref.1808008 
matic because they are waging a legal and peaceful struggle for their fundamental rights against the dispossession of their ancestral territories and its natural resources.

Keywords: multiculturalism, fundamental rights, Yaqui Tribe.

\section{Introducción}

El presente trabajo propone discutir el papel del multiculturalismo y los derechos fundamentales ante el despojo que sufren los pueblos indígenas de los recursos naturales y sus territorios ancestrales en una sociedad multiétnica y culturalmente diversa como la mexicana, a través del análisis de la tribu yaqui de Sonora. Dicho caso pone de manifiesto que a pesar del avance en la constitucionalización del derecho internacional de los pueblos indígenas, existe un incumplimiento y violación de ella por toda clase de actores públicos y privados en perjuicio de los yaquis. Dicha situación, que puede ser extensiva al caso de otros pueblos indígenas de México y de Iberoamérica, reclama importantes cambios en el orden legal, político e institucional para convertir a los pueblos indígenas en un asunto prioritario del mayor interés público, dada su significación e importancia histórica, así como los rezagos y problemas sociales, políticos y jurídicos que sufre esta población, pero que también afectan en mayor o menor medida, a la ciudadanía en general.

Durante los años pasados, las diferentes sociedades del mundo han conocido una irrupción de movimientos sociales indígenas, en especial de los derechos humanos fundamentales referidos a los pueblos indígenas en el mundo, ${ }^{1}$ que son un tema de creciente interés internacional por sus múltiples implicaciones sociales, mismas que van desde lo constitucional hasta lo ambiental, pasando por lo político o lo cultural.

Entonces, la hipótesis que se plantea, consiste en sostener que a pesar del reconocimiento constitucional por parte del Estado mexicano de los tratados internacionales como fuentes de derechos fundamentales, con plena vigencia en el orden jurídico interno y de la reconocida plurinacionalidad de la nación mexicana en la propia Constitución vigente, el caso del despojo ilegal de recursos naturales a la tribu yaqui de Sonora, demuestra que el marco jurídico institucional del Estado nación mexicano no dispone de las herramientas jurídicas e institucionales para reconocer la diversidad y encausarla pacíficamente, respetando los derechos fundamentales de los pueblos indígenas, de los yaquis en particular, a la autonomía, a la justicia o a la consulta previa, libre, informada, de buena fe y con el propósito de obtener el consentimiento; así como el derecho a la protección de sus territorios ancestrales y los valiosos recursos naturales que contienen.

En el caso de México, el tema es especialmente importante por varias razones. Entre las principales está la fuerte presencia indígena en el actual territorio mexicano, pero también la suma de agravios e injusticias históricas de las que han sido víctimas

\footnotetext{
1 "Pueblos Indígenas" en términos de colectivos humanos que se autoidentifican como una comunidad originaria en el contexto de un estado nacional (C169-Convenio sobre pueblos indígenas y tribales, 1989, (1991); Corte Interamericana de Derechos Humanos [Corte IDH] (s.f.); Declaración de las Naciones Unidas sobre los Derechos de los Pueblos Indígenas, 2007).
} 
los indígenas, ${ }^{2}$ lo que los convierte en minorías sociales altamente vulnerables por sus condiciones de atraso, marginación y pobreza. De ello deriva en gran medida la creciente conflictividad social asociada a estos pueblos en nuestros días, así como la preocupación actual sobre la legitimidad o la legalidad de los modelos de crecimiento económico dominantes, que privilegian la extracción de recursos naturales sin contar con la consulta o el consentimiento previo de las poblaciones asentadas en los territorios de extracción o de los pueblos originarios que pueblan ancestralmente dichos territorios, situación que entraña riesgos crecientes a la propia existencia de la tribu yaqui. Así, el derecho a la libre determinación o a la consulta previa, libre e informada, al igual que el acceso a la tierra y el territorio o a la justicia expedita, son derechos fundamentales de los pueblos indígenas, pero también deberes legales exigibles para los Estados nación según las normas del derecho internacional.

A continuación se presenta alguna evidencia y argumentación al respecto. Reconoce y estatuye el artículo $2^{\circ}$ de la Constitución Política de los Estados Unidos Mexicanos la plurinacionalidad de la nación mexicana, basada esencialmente en sus pueblos originarios. Por su parte, el artículo $1^{\circ}$ constitucional eleva al rango de derechos fundamentales en el orden interno a los derechos humanos reconocidos en los tratados internacionales desde 2011. Además, el primer párrafo del artículo $4^{\circ}$ constitucional reconoce explícitamente el derecho fundamental al medio ambiente sano, para enseguida reconocer también el derecho humano fundamental al agua potable y al saneamiento. ${ }^{3}$ Luego, si en el orden internacional el Estado nación mexicano ${ }^{4}$ es parte firmante de todas las convenciones y tratados internacionales en materia de derechos de los pueblos indígenas, ¿a qué se debe entonces la creciente conflictividad social en el entorno físico y geográfico de estos pueblos en México?, ¿cuáles son sus causas?, ¿tiene que ver con la violación al marco jurídico que les protege como sujetos colectivos de derechos? El caso de la tribu yaqui de Sonora es paradigmático porque sirve para validar en los hechos que los sistemas normativos vigentes que protegen los derechos de los pueblos indígenas no han sido instrumentados ni aplicados en el orden interno para respetar sus derechos fundamentales ante la oleada de proyectos extractivos, también llamados "megaproyectos" o "proyectos de desarrollo" implantados en los territorios ancestrales de los pueblos indígenas sin su conocimiento ni su consentimiento previo. Esto evidencia la ruptura del estado democrático de derecho y pone en entredicho la efectividad de dichas normas, así como la carencia de instituciones públicas interculturales y la vigencia entera del Estado de derecho en un Estado que se define como plurinacional y democrático y de derecho (Carbonell, 2010).

\footnotetext{
${ }^{2}$ No sería exagerado decir que el libro Brevísima relación de la destrucción de las Indias, escrito en 1552 por Bartolomé de las Casas y dirigido al príncipe Felipe de España, fue la primera relatoría sobre violación masiva de derechos humanos de la historia. La observación es de Jan Jarab, representante en México del Alto Comisionado de las Naciones Unidas para los Derechos Humanos (Oficina en México del Alto Comisionado de Naciones Unidas para los Derechos Humanos, 2018).

${ }^{3}$ El Comité de Derechos Económicos, Sociales y Culturales en las Observaciones Generales sobre el derecho al agua (DESC OG 15), ha establecido que:

Los Estados parte deberían garantizar un acceso suficiente al agua para la agricultura de subsistencia y para asegurar la supervivencia de los pueblos indígenas. En relación con estos últimos, se conmina a los Estados para que faciliten los recursos que les permitan a las comunidades planificar, ejercer y controlar su acceso al agua (Observación general $\mathrm{N}^{0}$ 15: El derecho al agua, s.f., arts. 11 y 12).

${ }^{4}$ Autodefinido como pluricultural (véase Constitución Política de los Estados Unidos Mexicanos, 2001, art. 2; Gutiérrez, 2018).
} 
En cuanto al despojo de recursos naturales en perjuicio de los territorios indígenas ancestrales, podemos decir en un contexto general para el presente trabajo, que para 2015 el mundo conoció un número aproximado de 1500 conflictos socioambientales documentados. Centrándonos en Iberoamérica, la mitad de dichos conflictos sucedía en el entorno de los estos pueblos, que están frecuentemente situados en las denominadas: "fronteras de la extracción" (Martínez, 2015). De esa constatación, realizada por diferentes grupos de trabajo en toda la región, parte la idea del presente trabajo. Según la Organización de las Naciones Unidas (ONU), existen en el mundo al menos 5000 grupos indígenas compuestos por unos 370 millones de personas, que viven en más de 70 países de los cinco continentes. Los pueblos indígenas de la región Iberoamericana suman actualmente unos 55 millones de personas, según la misma fuente, repartidas entre 33 países, mismas que hablan unas 300 lenguas originarias, según la misma fuente (oNU, s.f.).

En México, suman unos 16 millones de personas las que se autoreconocen como indígenas, pertenecientes a unas 65-68 etnias distintas, quienes representan aproximadamente 15-16\% de la población total del país (es un cálculo del Instituto Nacional de Geografía y Estadística [Inegi] para el caso de México, en 2015, con información de la Comisión Nacional para el Desarrollo de los Pueblos Indígenas [CDI]). Así que dada la gran diversidad étnica de su población, en México se habla todavía en 2018 unas 68 lenguas originarias además del español, que es la única lengua "oficial" del Estado mexicano. Sin embargo, en este contexto, los pueblos indígenas conforman una verdadera minoría discriminada; según el Inegi, 7 de cada 10 indígenas mexicanos viven en condiciones de pobreza (Inegi, 2016). Paradójicamente, la presencia indígena y su marginación y pobreza, es más importante en las regiones donde se concentran los mayores recursos naturales, ${ }^{5}$ que han captado la codicia del extractivismo doméstico y trasnacional, como demuestran, entre otros, el trabajo de Toledo, Garrido y Barrera-Bassols (2015) o de Martínez (2015); y así es como la situación de estos pueblos no es mucho mejor que en el pasado reciente, así lo establece, por ejemplo, el reciente informe del Banco Mundial (The World Bank, 2015).

\footnotetext{
${ }^{5}$ Las graves violaciones a los Derechos Humanos en contra de los pueblos y comunidades indígenas en México se dan en dos áreas principales: violencia en el contexto de megaproyectos en tierras y territorios ancestrales autorizados sin el debido proceso de consulta y consentimiento previo, libre e informado, o en el marco de reivindicación de sus tierras y falta al debido proceso penal. En varias ocasiones se ha denunciado el otorgamiento de concesiones de parte del Estado a empresas privadas en violación del Derecho a la Consulta Previa. Como consecuencia de la lucha por sus tierras, también se ha recibido información sobre la criminalización de defensoras y defensores de los Derechos de los pueblos y comunidades indígenas (Comisión Interamericana de los Derechos Humanos [CIDH] y Organización de los Estados Americanos [OEA], 2015, p. 124).
} 


\section{Multiculturalismo y derechos fundamentales}

El término multiculturalidad es uno de tantos que leemos y escuchamos repetidamente en lo cotidiano junto a otros como globalización, sustentabilidad o sociedad digital, por ejemplo. La multiculturalidad ${ }^{6}$ es también uno de los conceptos claves que se han extendido hacia muchas áreas del conocimiento social porque permite explicar mejor el mundo en que vivimos. El significado de la palabra, como se desprende de manera simple y literal, alude a la obvia existencia y coexistencia de muchas culturas en un lugar y tiempo determinados.

Sin embargo, más allá de esa sencilla definición, a partir de la década de los ochenta del siglo pasado, el término multiculturalidad ha sido empleado de diferentes maneras, en diferentes contextos y por diversos autores para caracterizar la situación actual de muchas poblaciones y sociedades en ciertos países del mundo, en especial de los más diversos culturalmente hablando (Calderón, 2009).

Desde una visión muy general, podemos decir entonces que el multiculturalismo puede definirse simplemente como la coexistencia dentro de un territorio de grupos minoritarios que reclaman el reconocimiento de su identidad y de su derecho a la diferencia a los respectivos estados nacionales que los han asimilado o hecho parte de sus súbditos o ciudadanos en algún momento de la historia (Kymlicka, 2007).

Así, según algunas estimaciones, más de $90 \%$ de los Estados que existen en el mundo contienen una pluralidad de grupos étnicos, lingüísticos o religiosos, lo que implica que menos de $10 \%$ de los Estados tienen una composición homogénea (Torbisco, 2000). De modo, sostiene Torbisco con razón, que la diversidad es más que un argumento, un rotundo hecho social difícil de debatir. Por eso es notorio que durante los pasados cuarenta o cincuenta años, el mundo fue testigo de una verdadera revolución en las relaciones entre los Estados nación y sus minorías étnico culturales, puesto que el viejo modelo de Estado, asimilacionista y homogeneizador, está siendo fuertemente cuestionado y en algunos casos sustituido, por nuevos modelos multiculturales de Estado y de ciudadanía, ${ }^{7}$ lo cual se ha visto reflejado, en algunos casos, en la aceptación de la autonomía y los derechos de las minorías nacionales, así como en el reconocimiento de demandas territoriales y derechos al autogobierno para los pueblos indígenas (Kymlicka, 2007). Es así que intentando mirar comprehensivamente al término multiculturalidad, es necesario para las ciencias sociales ampliar su campo hacia diversas disciplinas interconectadas para obtener una necesaria alimentación de otras ramas del conocimiento que permita averiguar la relevancia y la pertinencia de dicho término para el desarrollo regional, para la realización del estado democrático y social de derecho y desde luego, para la paz social, donde dicha paz pueda ser entendida positivamente, es decir: no solo como la ausencia de violencia, sino en términos de

\footnotetext{
6 "Multiculturalidad: Convivencia de diversas culturas" (Real Academia Española, 2016).

${ }^{7}$ Explicaba el filósofo Luis Villoro Toranzo que dos ideas fundantes conformaban la llamada "modernidad" y que ambas derivaban de un concepto universal de razón única, igual para todos los hombres en todas las épocas. Estas ideas fundantes eran, en primer término, la del Estado nación como protagonista absoluto de nuestro tiempo; y en segundo término, la idea del progreso constante de la humanidad hacia una cultura "racional". Pero el fin de la llamada modernidad y sus resultados actuales por todo el mundo, nos dejan ver que esas ideas de civilización y razón únicas llegaron a su fin. Así, el mundo no puede ser visto más como una palestra de lucha permanente y constante entre Estados nación, sino como una unidad de pueblos, de culturas y de etnias, donde es necesario comprender a la razón como el resultado de una pluralidad cultural inagotable.
} 
"paz positiva", como la define Johan Galtung: "Positive Peace, the counterpart to Negative Peace, is the presence of the attitudes, institutions and structures that create and sustain peaceful societies" (Galtung, 1996, p. 314).

De lo expuesto deriva la noción más reciente de la búsqueda de un denominador común, y de un estándar mínimo de irreductible dignidad humana, que pueda ser válido y aceptado por las sociedades del mundo o por la mayoría de ellas, con el riesgo que ello implica para la concepción occidental de los derechos humanos, al rechazar como "atípicos" los derechos colectivos de culturas diferentes o de minorías étnicas que preconizan desigualdades históricas (Santos, 1998). Si el derecho y las normas jurídicas se basan en valores comunes que afectan no solo a la organización básica de la sociedad, sino también la convivencia en un sistema jurídico coherente creado por un Estado soberano en el marco de un Estado nación más o menos homogéneo, entonces valdría preguntarse: ¿qué significa el multiculturalismo para las ciencias sociales en general y para las ciencias jurídicas en particular?, ¿puede significar desde el regionalismo, la reivindicación social y la política de las minorías visibles o invisibles hasta la construcción de una sociedad mundial "mestiza"? (Casorla, 2010). ¿Es posible un derecho que sea a la vez globalizado y "amestizado" o mestizo?, ¿cómo hacer frente a los desafíos del mercado global frente a los particularismos sociales y culturales? Con base en estas interrogantes, autores como Ferrajoli (2004), consideran que los derechos que por su importancia deben ser garantizados son aquéllos cuya defensa es necesaria para la paz, los derechos de igualdad de las minorías que garantizan el multiculturalismo y los derechos que protejan a los débiles frente al más fuerte (Ferrajoli, 2006).

Así, el Estado no solo debe garantizar los derechos fundamentales frente a los diferentes niveles de actuación y autoridad pública, sino también y sobre todo frente a los privados, incluyendo en ello los derechos económicos, sociales, culturales y ambientales en el marco del derecho internacional (los llamados DESCA) $;^{8}$ de manera que se haga frente a la crisis de un constitucionalismo que parece impotente ante los efectos de una "globalización localizada" (Santos, 1998) en un sistema-mundo en el que los países subalternos o en desarrollo se caracterizan por no tener reglas ni controles, lo que acentúa las diferencias entre los países, entre las regiones y entre las personas, polarizando peligrosamente a las sociedades nacionales, como es el caso de la población mexicana (García, Fuentes y Montes, 2012).

En el caso del Estado nación mexicano, este se autodefine como "pluricultural" en su Constitución Política desde 2001 en los siguientes términos:

La Nación tiene una composición pluricultural sustentada originalmente en sus pueblos indígenas que son aquellos que descienden de poblaciones que habitaban en el territorio actual del país al iniciarse la colonización y que conservan sus propias instituciones sociales, económicas, culturales y políticas o parte de ellas (Constitución Política de los Estados Unidos Mexicanos, 2001, art. $2^{\circ}$ ).

Por otra parte, la reforma constitucional de 2011 asumió a los derechos humanos derivados de todos los pactos internacionales y convenciones suscritos por el Estado mexicano, en norma constitucional. Así, estatuye el artículo $1^{\circ}$ Constitucional:

\footnotetext{
${ }^{8}$ Estatuidos en el Pacto Internacional de Derechos Económicos, Sociales y Culturales, (PIDESC), adoptado por resolución de la Asamblea General de las Naciones Unidas en 1996 e incluidos luego en el Sistema Interamericano de Protección mediante el llamado Protocolo de San Salvador de 1998.
} 
En los Estados Unidos Mexicanos todas las personas gozarán de los derechos humanos reconocidos en esta Constitución y en los tratados internacionales de los que el Estado Mexicano sea parte, así como de las garantías para su protección [...] Las normas relativas a los derechos humanos se interpretarán de conformidad con esta Constitución y con los tratados internacionales de la materia favoreciendo en todo tiempo a las personas la protección más amplia. Todas las autoridades, en el ámbito de sus competencias, tienen la obligación de promover, respetar, proteger y garantizar los derechos humanos de conformidad con los principios de universalidad, interdependencia, indivisibilidad y progresividad (Constitución Política de los Estados Unidos Mexicanos, 2011, art. 1).

Ahora bien, según diversas fuentes e indicadores, el México actual adolece de un Estado democrático de derecho consolidado, descrito así:

México atraviesa una grave crisis de violencia e inseguridad desde hace varios años. [...] el inicio durante el 2006 de la llamada "guerra contra el narcotráfico", las graves situaciones de violencia aumentaron hasta alcanzar niveles alarmantes, incluyendo la consecuente pérdida de más de cien mil personas, miles de desapariciones, y un contexto que ha provocado el desplazamiento de miles de personas en el país (Comisión Interamericana de Derechos Humanos [CIDH] y Organización de los Estados Americanos [OEA], 2015, p. 124).

O bien: "México ocupa el lugar 92 entre 113 países analizados", según el estudio: The Rule of Law Index 2017-2018 (World Justice Project, 2018, p. 17); situación que se ve acompañada de una creciente complejidad y una severa crisis social, económica y política (Ackerman, 2016).

\section{Multiculturalidad y derechos de las minorías}

El concepto originalmente sociológico, que no jurídico, de la multiculturalidad fue ideado en Canadá y en los Estados Unidos de América, Estados nación federados y países de inmigrantes, multilingües y multiculturales por naturaleza desde su propia fundación. Así que en el amplio panorama teórico del multiculturalismo (Arango 2002; Cortina, 2005; Sartori, 2001), destacan por su carácter de referente las tesis de Kymlicka dentro de la corriente denominada liberalismo multicultural. Tesis que podría encuadrarse dentro del marco teórico del liberalismo político (Rawls, Gray, Taylor) y de los principios liberales de la tolerancia, en virtud de los cuales se plantea la neutralidad del Estado frente a las diversas opciones individuales respecto a lo que ha de ser una "buena vida". Para Kymlicka (1996) un Estado es multicultural tanto cuando sus miembros pertenecen a naciones diferentes, situación que dicho autor denomina "Estado multicultural"; como cuando por causa de emigración personal o familiar provengan de otras naciones, situación considerada "Estado poliétnico". Por lo tanto, siguiendo al citado autor, las diferencias nacionales y étnicas constituyen la columna vertebral del multiculturalismo. Bajo tales directrices, una sociedad sustentada en los principios de la tolerancia liberal debería tratar a todos los que la integran con igual consideración y respeto, como pide expresamente la Constitución 
italiana en su artículo $3^{\circ}$, sustentando el principio de teoría constitucional de igualdad formal ante la ley:

Todos los ciudadanos tendrán la misma dignidad social y serán iguales ante la ley, sin distinción de sexo, raza, lengua, religión, opiniones políticas ni circunstancias personales y sociales. Constituye obligación de la República suprimir los obstáculos de orden económico y social que, limitando de hecho la libertad y la igualdad de los ciudadanos, impiden el pleno desarrollo de la persona humana y la participación efectiva de todos los trabajadores en la organización política, económica y social del país (Constitución de la República italiana, 1948, art. $3^{\circ}$ ).

Así pues, desde la óptica liberal, resultaría inadmisible la existencia de un dualismo social que estratificase a los ciudadanos en función de su pertenencia grupal y cultural en ciudadanos de clase A (los pertenecientes a los grupos mayoritarios y dominantes) y ciudadanos de clase B (los pertenecientes a grupos minoritarios, marginales o relegados). Para evitar dicho dualismo, se haría necesaria la construcción de un entorno positivo al reconocimiento mutuo y recíproco entre ciudadanos. Este contexto positivo tendría que posibilitar que los ciudadanos (independientemente de cuál sea su grupo de adscripción) se perciban como iguales y se reconozcan entre sí (Taylor, 1993). Entonces el multiculturalismo aflora en el derecho cuando este se convierte en multiculturalista, es decir, cuando el Estado no constituye más el marco de los individuos, sino de grupos que anidan "solidaridades y valores comunes", de manera que se debe legislar para o en contra de los grupos paralelamente al derecho de los individuos. Esto "debilita" en la óptica liberal el principio clásico de igualdad ante la ley ${ }^{9}$ de la teoría constitucional presente en muchas constituciones del mundo, y aún en numerosos tratados y convenciones internacionales. ${ }^{10}$

Por otra parte, la teoría liberal de la multiculturalidad alude al principio llamado del "acomodamiento razonable", que es una noción jurídica anglosajona, concretamente canadiense, que permite poner a prueba la capacidad del derecho para gestionar el pluralismo, pues es cierto que el llamado "comunitarismo" (que es una influencia mayor en la filosofía política contemporánea; la cual, contrariamente al liberalismo, el comunitarismo critica al individualismo y a la neutralidad estatal, y defiende una idea del bien común) puede cambiar todo el sistema de referencias sociales (Santiago, 2010).

Esto porque el humanismo de la ilustración, siguiendo la idea de Kant, también presente ya en el pensamiento de Rousseau - aunque luego eliminada por el discurso liberal- (Santos, 1998), pretendía construir la identidad no en relación con la tradición

\footnotetext{
9 "Los hombres nacen y permanecen libres e iguales en derechos", estableció el artículo $1^{\circ}$ de la Declaración de los Derechos del Hombre, aprobada por la Asamblea Nacional francesa (Declaración de los Derechos del Hombre y del Ciudadano de 1789,1789 , art. $1^{\circ}$ ). Este es sin duda el punto de partida del constitucionalismo moderno y de la teoría liberal del estado.

${ }^{10}$ Es el caso del artículo $4^{\circ}$ de la Convención Americana sobre Derechos Humanos suscrita en la Conferencia Especializada Interamericana sobre Derechos Humanos (B-32) (1969), que señala: "Todas las personas son iguales ante la ley. En consecuencia, tienen derecho, sin discriminación, a igual protección de la ley." También el del artículo 26 del Pacto Internacional de Derechos Civiles y Políticos:

Todas las personas son iguales ante la ley y tienen derecho sin discriminación a igual protección de la ley. A este respecto, la ley prohibirá toda discriminación y garantizará a todas las personas protección igual y efectiva contra cualquier discriminación por motivos de raza, color, sexo, idioma, religión, opiniones políticas o de cualquier índole, origen nacional o social, posición económica, nacimiento o cualquier otra condición social (Pacto Internacional de Derechos Civiles y Políticos, 1976, art. 26).
} 
y a la memoria, sino basándose en los principios que constituyen la libertad de los miembros de una comunidad, la sumisión de todos a una legislación general y única, y la igualdad de todos en su calidad de ciudadanos. Pero la teoría de la primacía de la comunidad sobre el individuo, implica que esta deber ser erigida en sujeto de derecho, siendo el individuo definido por los valores del grupo, contexto en el que ejerce su libertad. Tal concepción desafía la noción de neutralidad de las instituciones públicas cuando el Estado decide imponer políticas basándose en cultura, religión o tradición. Así que el término "sociedad multicultural" designa pues a una sociedad plural marcada por la diversidad de los grupos que la componen y que reclaman no perder su identidad. Esto se opone claramente a la tradición francesa de la asimilación y a la concepción pluralista anglosajona, que persigue la cohesión social y la unidad nacional a través de la inclusión de la diversidad, donde las identidades culturales no solo son reconocidas y toleradas públicamente, sino a veces incluso institucionalizadas. Así que ante la postura del llamado "realismo jurídico" que planteaba la necesidad para el Estado de reconocer la homogeneidad de sus ciudadanos, tal parece que hoy la multiculturalidad jurídica pasa por el reconocimiento de la diferencia y de la multietnicidad, que es lo que preserva lo llamado "étnico". Se dice pues que idealmente, en un proceso de articulación más favorable de una etnia con el Estado, aquella no requiere tener una identidad compartida, sino la identificación de un pueblo indígena como hablante y del Estado como oyente. ${ }^{11}$ Ambos se encuentran con el objetivo del pueblo indígena, pero también del Estado, de un reconocimiento expreso que quede incorporado a las normas constitucionales y por consiguiente al resto del sistema jurídico. Así pues, la idea de multiculturalidad de corte liberal daría paso a la idea de interculturalidad, que se define básicamente como una práctica horizontal de diálogo entre diversos pero iguales. La interculturalidad significa entonces un modelo de sociedad que defiende tres principios: 1) la igualdad de oportunidades de todas las personas para compartir un espacio y vivir en él, 2) el respeto a la diversidad y 3) la creación de entornos sociales que faciliten el intercambio y el enriquecimiento mutuo de sujetos con diferentes orígenes étnicos o culturales. Son "todas aquellas situaciones en las que se opta por la no violencia” (Jiménez, 2016, p. 19). Al respecto, ya señalaba Habermas que en general la discriminación puede abolirse no mediante las independencias, mismas que por lo demás tampoco han sido reclamadas históricamente por los pueblos indígenas mexicanos, sino a través de una inclusión que sea suficientemente sensible a las diferencias culturales específicas, tanto individuales como de grupo. El asunto de las minorías que "aparecen" o "pueden aparecer" en cualquier sociedad plural y que se agudiza en las sociedades formadas por muchas culturas diferentes, significa que cuando dichas sociedades están organizadas como Estados democráticos de derecho, siempre se ofrecen caminos para la inclusión sensible de las diferencias, como la repartición federal-regional de poderes, el traspaso de competencias específicas, las autonomías entendidas como los derechos específicos de cada grupo, la discriminación positiva, la igualación, y otras políticas para la protección de las minorías. Pero la inclusión pasa siempre por normas que rompan con la subordinación que cambie las normas institucionalizadas, reconociendo las diferencias (Habermas, 1999). Con todo, casi nada de esto ocurre todavía en México en relación con sus pueblos originarios; por eso importa plantear en dicho contexto nacional las ideas tomadas de los debates sobre la multiculturalidad y la interculturalidad.

${ }^{11}$ De reconocimiento, diría Habermas. 


\section{Derechos fundamentales de los pueblos indígenas}

¿Cómo ha impactado el desarrollo del derecho internacional de los derechos humanos y su aplicación por cada Estado nación?, ¿qué ha ocurrido con los derechos fundamentales de los pueblos originarios de Las Américas durante la existencia del Sistema Universal (1948) y del Sistema regional de protección de derechos humanos (Declaración Americana de los Derechos y Deberes del Hombre de 1948), Carta de la Organización de los Estados Americanos (1948) y la Convención Americana sobre Derechos Humanos (1969)?

Gracias en gran medida al movimiento por los derechos humanos iniciado con la Declaración de 1948, los pueblos indígenas "irrumpieron" (Bengoa, 2009) en el escenario internacional, reclamando su espacio como verdaderos sujetos de derecho internacional (Gómez, 2002). Así, la presencia y autoadscripción indígena está viva en casi todas las regiones de México; en 2015, 6.5\% de la población de tres años o más (sobre la cifra total de población), hablaba alguna lengua indígena, mientras que 24.4 millones de personas se auto reconocían como indígenas (Inegi, 2016). Luego de siglos de marginación o en el mejor de los casos, de asimilación paternalista, conforman una verdadera minoría discriminada. Paradójicamente, dicha presencia indígena con sus rasgos históricos de pobreza y marginación es más importante donde se concentra la mayor parte de la riqueza en términos de recursos naturales ${ }^{12}$ que desde luego han captado la codicia del extractivismo doméstico y trasnacional, como demuestran, entre otros, el trabajo de Stavenhagen (1992), Toledo et al. (2015) o de Martínez (2015). Así es como la situación de los pueblos indígenas en 2016, más de 20 años después del levantamiento indígena de los Altos de Chiapas, no era mucho mejor que en el pasado reciente (The World Bank, 2015).

Entre las deliberaciones hechas por los propios pueblos indígenas de México, se ofrecía un balance en agosto de 2014 que retrataba hasta 29 casos de despojo y movimientos de resistencia en curso, que fueron acompañados de un informe sobre criminalización, asesinatos, desapariciones y hostigamientos de diversa índole:

En la actualidad, los capitalistas neoliberales, con el apoyo de todos los partidos políticos, y los malos gobiernos, están aplicando las mismas políticas de despojo a gran escala que aplicaron los liberales del siglo xix, los carranzas, los obregones, apuntalándose en la militarización y paramilitarización, asesoradas por los cuerpos de inteligencia estadounidense en aquellas regiones donde las resistencias se enfrentan al despojo (...) Nadie va a venir a salvarnos, nadie, absolutamente nadie va a luchar por nosotros. Ni partidos políticos, ni políticos ni leyes, ni nada hay para nosotros (Bermejillo, 1997).

\footnotetext{
${ }^{12}$ Las graves violaciones a los Derechos Humanos en contra de los pueblos y comunidades indígenas en México se dan en dos áreas principales: violencia en el contexto de megaproyectos en tierras y territorios ancestrales autorizados sin el debido proceso de consulta y consentimiento previo, libre e informado, o en el marco de reivindicación de sus tierras y falta al debido proceso penal. En varias ocasiones se ha denunciado el otorgamiento de concesiones de parte del Estado a empresas privadas en violación del Derecho a la Consulta Previa. Como consecuencia de la lucha por sus tierras, también se ha recibido información sobre la criminalización de defensoras y defensores de los Derechos de los pueblos y comunidades indígenas (CIDH y OEA, 2015, p. 124).
} 
También sabemos que las viejas o las nuevas demandas indígenas transformadas ahora en movimientos sociales en Iberoamérica y también en México, no pasan necesariamente por la independencia ni por la configuración de Estados nacionales indígenas; sino por el reconocimiento pleno de sus derechos, que también son deberes de los Estados en el ámbito internacional (y aun en el interno). Concretamente, por reconocimiento y el respeto del derecho a la autonomía, a la consulta previa, libre, informada y de buena fe, y al uso y disfrute de territorios y tierras. Estos derechos están plenamente reconocidos por el corpus juris del Sistema internacional y regional de derechos humanos (Convenio Núm. 169 de la oit sobre pueblos indígenas y tribales (2014) sobre los derechos de los pueblos indígenas, Declaración Americana sobre los derechos indígenas, y Convención Internacional sobre toda forma de discriminación racial [ICERD]) y también por la práctica de la CIDH y la jurisprudencia de la Corte Interamericana de Derechos Humanos.

Ya Jurgen Habermas señalaba que una razón comunicativa está presente en las relaciones cotidianas, y es la que permite encontrar acuerdos o aplazar la solución de conflictos, mayor democracia y mejor equilibrio social piden la reforma de las normas democráticas, donde un Estado de Derecho no solo lo sea en las normas, sino también de hecho, pues existe tensión entre los planteamientos normativistas que siempre corren el riesgo de perder el contacto con la realidad y los objetivistas, que eliminan todos los aspectos normativos. Para resolver los conflictos surge entonces la regulación normativa en la interacción social compleja que es lo que convierte al derecho en una categoría de la mediación social. Este es para Habermas, el problema de la facticidad y de la validez del derecho en una democracia (Habermas, 1988).

Pero transcurrido casi el primer cuarto del siglo xxI, resulta que esta nación autodefinida formalmente como "pluricultural" en su Constitución Política, es escenario de una inacabada transición democrática y de todo tipo de actividades extractivas de origen privado y público, ${ }^{13}$ lo que deja a las sociedades nacionales - especialmente a los sectores y minorías más vulnerables, como son los pueblos indígenas- secularmente en grave riesgo de rezago y exclusión social (Ackerman, 2016). ${ }^{14}$

Entonces, exterminar o condenar a la migración forzada no parecen alternativas válidas y aceptables hoy en día para abordar los asuntos indígenas, no solo porque implican graves violaciones a los derechos fundamentales de amplios grupos

\footnotetext{
${ }^{13}$ Las sociedades de finales del siglo XVI estuvieron marcadas por la "mundialización" derivada de la conquista y colonización de América, caracterizada por un comercio triangular entre Europa, América y África que luego fue reproducido en los enclaves europeos en Asia. La "nueva" mundialización contemporánea se caracteriza por la marginación de amplios sectores, la explotación intensiva de la mano de obra, la ruptura del tejido social y el tráfico de seres humanos. Una de las paradojas de la mundialización es que el fenómeno se pretende global cuando en el fondo es particular y preconiza un pensamiento único asociado a un modelo económico y social basado en el paradigma occidental, y especialmente, intentando reproducir el modelo norteamericano (Gómez, 2002).

${ }^{14}$ La historia moderna del territorio que hoy se constituye como los Estados Unidos Mexicanos, inicia con un proceso que bien se podría denominar, citando el término acuñado por David Harvey (2004), de "acumulación por despojo", donde la extracción colonial vincula al territorio con un sistema global interconectado, que se fundamenta en la acumulación y en la circulación de capital. Este despojo acontece por siglos, y no se refiere solo a la extracción externa, sino a la interna. Expulsión forzada de campesinos y pueblos originarios, pérdida de los derechos de comunidad, y transformación de las diversas formas de propiedad en una sola: la privada. Dicha acumulación suprime formas de producción y consumo alternativas, monetariza el valor de intercambio, e introduce la esclavitud, el comercio, los bancos, la deuda y un sistema crediticio generalizado.
} 
minoritarios, sino porque los pueblos indígenas se movilizan en su propia defensa más que nunca y movilizan también a otros actores sociales no indígenas dentro y fuera de México en solidaridad con sus causas, luchando contra la violación secular de sus derechos fundamentales con muchas de las herramientas jurídicas y no jurídicas del Estado de corte liberal, haciéndose visibles, empoderándose socialmente y captando mayores solidaridades entre el resto de la sociedad mayoritaria. Tal vez uno de los casos más notorios, transcurrido ya casi el primer cuarto del siglo xxi, ha sido la lucha yaqui, que en el siglo xxi ha sido legal y pacífica, a diferencia de las guerras de finales del siglo xIx y principios del xx. Ciertamente, el tema indígena irrumpe irremisiblemente en las realidades nacionales de cada vez más países, o como los define Bengoa (2009): una "emergencia indígena", donde el caso mexicano es especialmente señalado por muchas razones, como su alta diversidad étnica y lingüística, pero también coincide en sus características con un patrón de lucha continental contra el despojo de territorios y recursos naturales.

Podemos decir así con base en la evidencia del caso yaqui en el contexto mexicano, que las reformas constitucionales de 2001 y 2011 (que dieron cabida al reconocimiento plurinacional de la nación, así como al reconocimiento del marco internacional de los derechos humanos en el régimen interno), no han sido suficientes para garantizar la existencia de un derecho alternativo que pase por el reconocimiento de los pueblos indígenas como naciones antes que como culturas, que es justamente una de las reivindicaciones expresas que reclaman históricamente grupos minoritarios, como la tribu yaqui (Meyer, 2014). Pero la tendencia internacional seguida por las convenciones y pactos internacionales y por los sistemas regionales de protección de los derechos humanos, apuntan a reforzar el derecho ya asentado en el foro internacional a la libre determinación de los pueblos, donde se "transversalizan" los derechos indígenas a través de los textos constitucionales (Declaración de las Naciones Unidas sobre los derechos de los pueblos indígenas, 2007).

De manera que ahora el constitucionalismo plurinacional (Yrigoyen, 2011) plantea reconocer estas diferencias en dos planos: la enunciación en la dogmática constitucional, por una parte, pero también y de manera importante, en las garantías de ejecución y procedimientos de implementación, propios de la parte orgánica de una Constitución. ${ }^{15}$ Esto podría explicarse atendiendo al argumento de que desde la perspectiva monista del Estado y del derecho, la incorporación de la categoría de los derechos colectivos de los pueblos indígenas al derecho nacional de cada país generaría una serie de preguntas sobre su naturaleza y su vínculo con los derechos individuales, con los que chocaría frontalmente. Pero otros lo han definido más como un problema teórico que práctico. Rodolfo Stavenhagen lo veía como un tema explicable a través de la relación núcleo-periferia, donde el núcleo son los derechos individuales y la periferia los derechos colectivos, pues el cumplimiento de los primeros depende necesariamente del de los segundos. Así, en tanto análogos, no se contraponen, sino que se complementan, explicaba el autor citado (Stavenhagen, 1992). La visión de

\footnotetext{
${ }^{15}$ En el caso concreto, la Constitución Política de los Estados Unidos Mexicanos, que después de la irrupción indígena zapatista de 1994 en los Altos de Chiapas, reconoció a la Nación como pluricultural, al tiempo que estatuyó una serie de derechos constitucionales en favor de los pueblos indígenas, pero no mucho más que esos reconocimientos declarativos que 14 años después no encuentran articulación, desarrollo normativo ni garantías claras de ejercicio y cumplimiento en el sistema jurídico nacional, como demuestra el caso de los conflictos de los diferentes actores públicos y privados contra los pueblos indígenas de México.
} 
Stavenhagen concuerda esencialmente con el contenido esencial del artículo 8.2 del Convenio Núm. 169 de la ort sobre pueblos indígenas y tribales (2014): "Dichos pueblos deberán tener el derecho de conservar sus costumbres instituciones propias siempre que estas no sean incompatibles con los Derechos Fundamentales definidos por el sistema jurídico nacional ni con los Derechos Humanos internacionalmente reconocidos".

La realidad parece sin embargo caminar por otra dirección, puesto que las llamadas "reformas estructurales", las múltiples concesiones mineras, los trasvases de agua, los megaproyectos de urbanización (agroindustriales, turísticos o de infraestructura) autorizados por los gobiernos de todos los niveles y colores políticos a lo largo y ancho de México sin contar con la consulta y el consentimiento previo, informado, de buena fe y con el fin de obtener el consentimiento de los pueblos indígenas, cuando dichos proyectos les afectan de modo evidente; lo que plantean un serio desafío a la existencia misma de tales pueblos.

Este ha sido el caso del proyecto de trasvase de agua entre cuencas a través de la construcción de un acueducto en el río Yaqui (denominado "Acueducto Independencia" por el gobierno de Sonora), sin que haya existido una información ni una consulta previa, libre, informada, de buena fe y con el propósito de obtener el consentimiento de la tribu, como ordena claramente el estándar establecido por los tratados y convenciones internacionales y la jurisprudencia de la Corte Interamericana. Sin embargo, dicha normativa fue suscrita y ratificada por el Estado mexicano, razón por la que le obliga internacionalmente. Por ejemplo, el Convenio Núm. 169 de la oit sobre pueblos indígenas y tribales (2014), ha sido interpretado progresivamente ${ }^{16}$ por la CIDH de manera reiterada en muchos casos a lo largo del continente. Como ejemplos relevantes, constan algunas sentencias paradigmáticas de la Corte Interamericana de Derechos Humanos como: Masacres de Río Negro versus Guatemala, Saramaka versus Surinam, Kuna y Emberá versus Panamá, Belo Monte versus Brasil (Corte IDH, s.f.). Ante ello, la lucha yaqui y los movimientos indígenas en general se rearticulan regionalmente con otros movimientos nuevos, ya sean altermundistas, anarquistas, pacifistas, feministas o ecologistas, para enfrentar la dinámica del conflicto planteado por la agresión a sus territorios ancestrales, a los valiosos recursos naturales que contienen, y a sus modos de vida tradicionales, donde el Estado no ha sido capaz de cooptar con sus métodos corporativos tradicionales a los movimientos indígenas organizados, muchos, en el caso mexicano, articulados y agrupados ahora a través del Congreso Nacional Indígena (CNI), cuyo origen se remonta al Foro Nacional Indígena convocado en 1996 por el Ejército Zapatista de Liberación Nacional (EZLN).

Así, cada vez, un número mayor de indígenas mexicanos se plantea también, además del acceso a la tierra para trabajarla y un acceso colectivo a la propiedad, el legítimo derecho a un territorio autónomo que les permita reproducir su cultura. La figura del territorio es reconocida parcialmente por el Convenio Núm. 169 de la orT sobre pueblos indígenas y tribales (2014), como se ha dicho, convenio ya ratificado por el Estado mexicano, y al que los indígenas mexicanos se han aferrado en los litigios emprendidos a lo largo y ancho del país. Debe aclararse aquí, en palabras del abogado de origen mixteco Francisco López Bárcenas que:

\footnotetext{
${ }^{16}$ Interpretación progresiva o evolutiva significa en lo general, aquella que el juez o los jueces practican no solo conforme a derecho, sino apelando a la justicia y adaptando las normas a la realidad concreta que se va a juzgar.
} 
La propiedad de los pueblos indígenas es de carácter predominantemente colectivo, se distingue de otro tipo de propiedades por su rasgo cultural más que económico, y su fundamento no es el reconocimiento del Estado, sin dejar de reconocer que éste tiene la obligación de proteger tal derecho, sino la posesión de ellas con base en su propio derecho consuetudinario. Como puede verse, el reconocimiento jurídico de la existencia de este tipo de propiedades marca una diferencia radical con el tipo de propiedad privada, cuya naturaleza es de carácter individual, su existencia obedece a una necesidad económica de acumulación y su fundamento está en el reconocimiento estatal de ellas" (López, 2015, 121).

O en palabras de Villoro: "no existe contradicción entre los derechos individuales y los colectivos, sino que son los segundos los que sientan las bases para que los primeros florezcan" (Villoro citado en Bermejillo, 1997).

\section{Violación y defensa de los derechos fundamentales de la tribu yaqui}

En el actual estado de Sonora, existen nueve grupos étnicos originarios de la región, que en conjunto suman unas 138000 personas, mismas que representan alrededor de $5 \%$ de la población total del estado. De ellos, unos 51000 son yaquis (Zárate, 2016). En consonancia con la situación nacional, los pueblos indígenas representan el grupo social con mayor rezago social también en Sonora, como sucede en el resto del país.

Luego, resulta que también, como ocurre a nivel nacional, el estado de Sonora se reconoce en su Constitución política (al igual que lo hace la Constitución Política de los Estados Unidos Mexicanos) como un estado pluricultural que está fundado en sus pueblos originarios, a los que deberá poner especial atención en sus demandas (Luque et al., 2012, p. 60):

El estado de Sonora tiene una composición pluricultural sustentada originalmente en los pueblos indígenas, que son aquellos que descienden de poblaciones que habitaban en el territorio actual del Estado al momento de iniciarse la colonización y que conservan sus propias instituciones sociales, económicas, culturales y políticas, o parte de ellas. Esta Constitución reconoce y garantiza el derecho de los pueblos y las comunidades indígenas a la libre determinación y, en consecuencia, a la autonomía.

Sin embargo, es conocido que a lo largo de la historia de la región noroeste de México, La tribu yaqui, asentada en ocho pueblos o comunidades en la margen derecha del río homónimo dentro del territorio del actual estado de Sonora, sobrevivió siempre hasta ahora a la guerra, el destierro y la esclavitud. Así, después de la lenta y tardía colonización del noroeste mexicano, ya que la región fue considerada por el gobierno virreinal como parte de un "Gran Norte" remoto (Jiménez, 2006), desprovisto de ciudades o poblados importantes que conquistar, e inhóspito.

Entre 1790 y 1832 y luego entre 1876 y 1909, los yaquis sostuvieron conflictos armados (las llamadas "Guerras del Yaqui") contra el gobierno virreinal y también contra los diferentes gobiernos de Sonora. Finalmente también contra el gobierno nacional del entonces presidente, general Porfirio Díaz, cuya política contra los yaquis (rendición incondicional o bien guerra, muerte o destierro) no fue diferente de 
los anteriores, pues dichos gobiernos favorecieron en perjuicio del interés yaqui a diversos latifundistas y terratenientes locales y foráneos, que se apoderaron con el beneplácito oficial de la mayor parte del territorio originario de la tribu. Así, después de ser diezmados y vencidos militarmente en $1909,{ }^{17}$ un número considerable de miembros de la tribu fue deportado en condiciones de esclavitud o semiesclavitud a los campos de henequén de las haciendas en Yucatán o a las plantaciones de Oaxaca, en el sureste del país. La siguiente descripción procede del periodista norteamericano John Kenneth Turner, quien viajó desde California a la región yaqui en 1908:

Se extermina a los yaquis, y rápidamente. No hay lugar a controversia a este respecto: la única discusión posible se refiere tan sólo a si los yaquis merecen o no ser exterminados. Sin duda es cierto que una parte de ellos se ha negado a aceptar el destino que el gobierno les señaló. Por otra parte, hay quienes afirman que los yaquis valen tanto como cualesquier otros mexicanos y merecen la misma consideración por parte de sus gobernantes (Turner, 1910, pp. 37-38).

Así, se estima que más de 25000 personas, incluidas mujeres y niños, murieron en ese periodo, por lo que con estándares modernos sería dable calificar a este suceso como un genocidio en toda forma:

El Genocidio es un delito internacional que comprende cualquiera de los actos perpetrados con la intención de destruir, total o parcialmente, a un grupo nacional, étnico, racial o religioso. Estos actos comprenden la matanza y lesión grave a la integridad física o mental de los miembros del grupo, sometimiento intencional del grupo a condiciones de existencia que hayan de acarrear su destrucción física, total o parcial, medidas destinadas a impedir nacimientos en el seno del grupo, traslado por la fuerza de niños del grupo a otro grupo (Estatuto de Roma de la Corte Penal Internacional, 2002, art. 6).

Por eso es necesario recordar que en el caso de la tribu yaqui, ya no parece ser alternativa el acudir a la limpieza étnica practicada en el pasado (Padilla, 2011; Taibo II, 2014; Turner, 1910) ni un camino transitable por las autoridades y la sociedad mayoritaria; más aún cuando el caso yaqui, siendo uno de los más conocidos, no es ni mucho menos el único. ${ }^{18}$ En la misma región noroeste, y concretamente en Sonora, destacan otros casos relevantes y análogos al expuesto, como el de los macurawe (guarijíos) o los comcaac (seris) (Martínez, 2008) a quienes las concesiones extractivas otorgadas sin su consentimiento por los gobiernos recientes sobre sus territorios ancestrales, los han llevado a la migración forzada y casi el exterminio (Luque et al., 2012).

Resultado de esa larga historia de conflictos violentos en la región yaqui, producidos en una gran medida por la apropiación y el dominio de los recursos naturales, los yaquis consiguieron después de la Revolución mexicana la restitución de parte de sus

\footnotetext{
${ }^{17}$ Algunas fuentes hablan de una histórica y constante presencia de asentamientos yaquis en el territorio lo que hoy es Arizona, pero lo cierto es que existe al menos otro grupo importante de población autodefinida yaqui en la comunidad llamada "Pascua Yaqui". Dicho grupo huyó desde Sonora durante la persecución contra la tribu a principios del siglo xx y se asentó cerca de Tucson, Arizona. Posteriormente, los yaquis de Pascua Yaqui han sido reconocidos por el Gobierno de Estados Unidos como pueblo originario. Esto convierte a los yaquis en un pueblo indígena trilingüe, como otros del norte de México. Tal es el caso de los pimas (tohono o` odham) de Sonora, o los cucapás de Baja California.

${ }^{18}$ Véase por ejemplo a García (2015) o a Martínez, Murillo y Paré (2017).
} 
territorios ancestrales en 1937, mediante un decreto presidencial bajo el gobierno del general Lázaro Cárdenas, además de una cierta autonomía administrativa en 1939 (Lerma, 2014). Pero esos derechos ancestrales ya reconocidos fueron seriamente afectados en los pasados años por la deriva violenta y autoritaria de la crisis de derechos humanos ya señalada por la CIDH y otras organizaciones en México, así como por ese nuevo extractivismo solapado desde los diferentes estratos del Estado, (Lerma, 2014; Luque et al., 2012; Moreno, 2014). Pero también por la criminalización abierta o encubierta de la protesta y los liderazgos indígenas (López, 2014a; 2014b).

Así fue como durante los recientes años y especialmente desde 2010, a raíz del inicio de las obras del denominado Acueducto Independencia, la conflictividad social latente en la región yaqui escaló y adquirió mayor relevancia, dado el reavivamiento de la vieja contienda entre la tribu yaqui y otros actores sociales en Sonora (Moreno, 2014). Señaladamente contra el gobierno de ese estado y las diferentes dependencias y delegaciones del Gobierno federal en la región. ${ }^{19}$ La razón no era otra más que el inicio y ejecución por el gobierno estatal y una serie de empresas constructoras privadas de la región, de un megaproyecto consistente en las obras de un acueducto para el trasvase de agua del río Yaqui, en un medio natural caracterizado por sus altas temperaturas durante la mayor parte del año y conocido geográficamente como desierto de Sonora, ${ }^{20}$ donde el agua es un bien escaso y valioso, tal y como observaba la ввс en un reportaje titulado "Yaquis: Los combatientes de la primera guerra del agua en México" (Nájar, 2015).

Aunque es cierto que ya algunos estudiosos que vivieron antes entre los yaquis, en especial el antropólogo Spicer en la segunda mitad del siglo xx, habían notado una alta conflictividad latente por el tema del agua en dicha región desde mediados del siglo pasado, misma que no dudó en calificar tempranamente como "guerra del agua" ${ }^{21}$ antes de 1980, cuando apareció por primera vez su libro sobre los yaquis (Spicer, 1994). Es decir, que la guerra por el agua que parece cobrar súbita importancia en 2010 y en los años posteriores, era un conflicto previsible que tiene sus antecedentes varias décadas atrás, en el periodo posterior a la Revolución mexicana comprendido entre el año 1941, en que se terminó de construir en la cuenca del río Yaqui la presa La Angostura, y 1964, en que se terminó la de El Novillo, pasando por la de Oviachic en 1945 (Spicer, 1994). De modo que ante el escalamiento reciente del conflicto por el agua en la cuenca del río Yaqui, fue en 2010, cuando la tribu y otros actores sociales de la región comenzaron una resistencia pacífica y ciertas acciones legales en contra de las obras del llamado Acueducto Independencia, megaproyecto de infraestructura realizado por el gobierno de Sonora con el soporte del gobierno federal.

\footnotetext{
19 Dicho enfrentamiento, que ocurre históricamente entre yaquis y yoris (por exclusión, los que no son yaquis, pues en la idiosincrasia yaqui los otros, los yoris, son "los feroces" blancos y mestizos) no es nuevo, pues ha ocurrido en diferentes dimensiones en la historia de esa región desde el siglo XVI, con las primeras exploraciones europeas en el llamado "Gran Norte" de Nueva España, siempre asociado a la intermitente pero casi permanente disputa por el territorio y sus recursos naturales.

${ }^{20}$ El desierto de Sonora, (en inglés Sonoran Desert), está considerado el desierto más grande de América del Norte y, abarca un territorio comprendido por el noroeste de México y parte del suroeste de los Estados Unidos; en México gran parte de los estados de Sinaloa, Sonora y Baja California, en Estados Unidos California y Arizona, con una extensión aproximada de $310000 \mathrm{~km}^{2}$.

${ }^{21}$ El término "guerras del agua" ha sido generalizado posteriormente por la académica y activista Vandana Shiva en India, para referirse a la situación de crecientes grupos sociales desposeídos en India, pero que son situaciones análogas a muchas sociedades del mundo (Shiva, 2004).
} 
La idea del citado acueducto consistía básicamente en el trasvase hídrico, decidido por el gobierno de Sonora y sin informar ni consultar a los yaquis (Moreno, 2014), lo que evidentemente hace de la planeación y ejecución de dicho proyecto una violación a los derechos fundamentales de la tribu yaqui. Y no solo de ella, pues el derecho al agua potable y al saneamiento que se niega trasvasando agua para el consumo humano en los hechos, también vulnera derechos humanos fundamentales de la población en general —no únicamente indígena- de la región. De modo que es en esta etapa del renovado conflicto con los yaquis donde se observa no solo el nulo respeto al marco internacional y constitucional vigente por las autoridades de Sonora, sino la falta de una visión multicultural o mejor, intercultural, capaz de mediar efectivamente entre los actores en conflicto para buscar y encontrar soluciones y alternativas por efecto de las convenciones internacionales en los llamados "particularismos", regionales y locales, dadas las décadas de conflictos socioambientales en la región yaqui de Sonora.

Más de cien años después del cruento final de "las guerras del yaqui", los yaquis enfrentan actualmente la que podría ser una batalla definitiva por su supervivencia, pues luchan por conservar la integridad de sus territorios ancestrales y sus reservas de agua; pero a diferencia del pasado en que siempre optaron por la confrontación armada, lo han hecho hasta ahora por la vía pacífica, con las herramientas de movilización social y de impugnación legal a su alcance.

Es así como respaldados exiguamente por el marco legal vigente, sostienen que su existencia está en riesgo por la operación de un acueducto construido sin consultarles y sin su consentimiento. ${ }^{22}$ "Quitarnos el agua condenaría nuestra existencia en el corto y mediano plazo", señalaba Tomás Rojas, autoridad tradicional de la tribu (Nájar, 2015, párr. 4). "Tendríamos que salir de nuestras tierras. Si pensamos mal vemos una política de exterminio contra nosotros", denunciaba Rojas (Nájar, 2015, párr. 5). El gobierno de Sonora, sin embargo, sostenía que el acueducto era fundamental para abastecer de agua a la capital de Sonora, la ciudad de Hermosillo, y aducía que: "No se afecta a nadie, no se le quita una gota de agua a nadie y en cambio se resuelve el problema de escasez" (Nájar, 2015, párr. 7). Es claro sin embargo, que este conflicto trasciende el ámbito estatal e incluso nacional, porque el patrón de despojo de recursos hídricos es una constante en toda la región, según han podido documentar Martínez (2015) y Toledo et al. (2015).

Pero lo cierto es que la región yaqui, según se ha documentado, padece de lo que se denomina "estrés hídrico" por la sobreexplotación de sus recursos acuíferos ("Peritaje Antropológico", 2015), de manera que hasta ahora no se ha logrado conciliar el uso intensivo del agua con el derecho que tienen los yaquis, entre otras comunidades, a utilizarla para sobrevivir. Es por eso que el problema del agua en Sonora va más allá del acueducto que lleva el agua desde la presa El Novillo, dentro del territorio yaqui (Moreno, 2014); pues un decreto presidencial de 1940 le asignó a la tribu la mitad del caudal del río Yaqui, que es el más importante de la región (Lerma, 2014). Años más tarde, cuando crecieron las ciudades y aumentó la agricultura en la zona, se estableció

\footnotetext{
${ }^{22}$ No les importamos a los gobiernos corruptos, no les interesa nuestra salud ni nuestra supervivencia como pueblos ancestrales. Aquí en el yaqui diariamente miles de niños, mujeres, ancianos están obligados a consumir agua contaminada; mientras el mal gobierno acapara y desvía el río Yaqui; privilegia a otros, se lleva nuestra agua a las grandes ciudades donde la usan con fines industriales y la venden a ricos empresarios Agrícolas-Pecuarios y minas.... NAMAKASIA!!! (Luna, 2018).
} 
para la tribu una cuota de 250 millones de metros cúbicos al año. La mayor parte del agua se utiliza en campos agrícolas de la zona y, en 2010, se inició la construcción del citado acueducto para abastecer a la capital del estado.

La obra del acueducto fue impugnada legalmente desde el comienzo, pues los yaquis argumentaron que el gobierno estatal se apropió irregularmente de los permisos para aprovechar un recurso hídrico que les pertenece. Por su parte, las autoridades estatales han afirmado repetidamente que la asignación de esas concesiones es legal, algo que la Suprema Corte de Justicia de la Nación invalidó por sentencia firme, recaída en un juicio de amparo promovido por la tribu (Suprema Corte de Justicia de la Nación, s.f.). Sin embargo, dicha decisión de la Corte, que es firme y definitiva, no terminó con el conflicto, porque la obra y posterior funcionamiento del acueducto nunca se detuvieron, pese a las numerosas suspensiones provisionales y definitivas otorgadas por jueces y órganos jurisdiccionales federales. Finalmente, el acueducto impugnado entró en operación a pesar de las sentencias favorables obtenidas por los yaquis, por lo que la violación a sus derechos fundamentales ha sido continuada.

Pese a todo, la mencionada sentencia de la Corte marcó un indudable hito en la historia reciente de la lucha de los pueblos indígenas en México por el respeto de sus derechos fundamentales, porque por primera vez el más alto tribunal de la nación reconoció expresamente el derecho de los pueblos indígenas a ser consultados previamente ante la ejecución de proyectos de infraestructura que les afecten. A estas alturas, también es un hecho notorio que además de que el acueducto se construyó sin consultar previamente a la tribu, como ordenan las normas internacionales, las autoridades responsables no acataron las sentencias interlocutorias y definitivas que ordenaron suspender las obras y la posterior operación del acueducto.

Lo que sí hicieron las autoridades omisas con el fin de ganar tiempo para terminar las obras y poner en operación el acueducto, fue acudir a la Corte a pedir una cuestionada aclaración de la sentencia, pues en ella se les condenaba a consultar a la tribu. Ante dicha petición, la Corte ordenó al gobierno federal que realizara una consulta sobre el impacto de la obra en el medio ambiente de la zona afectada, algo que debería demostrar el posible daño que sufrirían los yaquis. Dicha consulta estaba en proceso en 2016, no sin repetidos cuestionamientos en su legitimidad por parte de la tribu. Ante la incertidumbre, y para defender el agua de un río que consideran literalmente la fuente de su cultura ancestral y de su vida colectiva, ${ }^{23}$ los yaquis bloquearon pacíficamente durante muchos meses la principal autopista del noroeste (México-Nogales) y realizaron caravanas a la Ciudad de México, además de la defensa legal emprendida. "Es una guerra de baja intensidad", decía el citado Tomás Rojas (Nájar, 2015), mientras los gobiernos estatal y federal continuaron con la operación del acueducto. Posteriormente, dos miembros conocidos de la tribu por su activismo Fernando Jiménez y Mario Luna, secretario y vocero de la autoridad tradicional, respectivamente, fueron detenidos y encarcelados. Se les acusaba de secuestro, en una preocupante criminalización del movimiento social emprendida en su contra por el

\footnotetext{
${ }^{23}$ Consideramos al río como un ser vivo, no como un conducto o un canal. Si deja de tener escurrimientos, lo dejas en agonía y condenado a la muerte. No solo el yaqui requiere esa agua para consumo propio, no existimos solo los humanos, también existen los animales y el bosque, además de un inframundo. El agua conecta al yaqui con el río y el espacio. Es un portal, si se le pudiera llamar así. Pero hablando desde el punto de vista biológico, se daña el ciclo hídrico, la humedad ambiente, las recargas al subsuelo y al microclima que alimenta mezquites, cactus, a nosotros y al subsuelo (Luna, 2017, párr. 14).
} 
gobierno de Sonora, en lo que significó, al parecer, una política de estado: reprimir la protesta y la movilización antes que resolver o dar cauce al conflicto social. Sin embargo, hasta ahora no queda claro si el acueducto dejará de funcionar, pues los procesos legales emprendidos por otros actores sociales de la región, igualmente afectados por el trasvase de agua, aún no terminan, pero todo parece indicar que el gobierno de Sonora no tiene ninguna intención de acatar las diversas sentencias emitidas. La tribu denuncia que unas 5000 hectáreas de su territorio están virtualmente muertas por una profunda salinización, ya que el cauce del río Yaqui se redujo drásticamente. Al respecto afirmaba Rojas: "La historia de nuestro pueblo siempre ha sido la lucha por la tierra y el agua” (Nájar, 2015, p. 38). A finales de 2015, los líderes yaquis habían sido liberados ante la falta de pruebas en su contra, después de pasar varios meses encarcelados y dada la amplia movilización social de apoyo a su causa, donde las protestas siguieron, si bien con menor intensidad que en 2013 y 2014, cuando se realizaron los mayores bloqueos carreteros. "Cualquier acción que vaya destinada a desaparecer, agredir o agraviar a los pueblos es una forma de guerra", subrayaba Tomás Rojas (Nájar, 2015, párr. 30).

Ejemplos como el expuesto han llevado al movimiento indígena a considerar prioritario luchar por la autonomía y la defensa de sus territorios ancestrales y sus recursos naturales frente al despojo de diversos actores sociales con poder económico y político. La resistencia se apoya también en diferentes estrategias como las jurídicas, que pasan por el litigio ante los tribunales, con resultados tan positivos como inefectivos hasta ahora (Ramírez, 2014).

Este panorama nos muestra que la mira de la lucha de estos pueblos está en la defensa de sus derechos autonómicos y territoriales y al acercar la lupa a cada uno se puede observar que su resistencia se apoya en diversas estrategias (...) Los acuerdos de San Andrés se convirtieron en el programa de los pueblos, que se expresa en la resistencia y estrategias de defensa y ni hablar de la razón de Estado que definió el suyo desde 2001 para ofrecer a los pueblos políticas asistencialistas, culturalistas que nada tienen que ver con la autonomía y la libre determinación. Por ello no respetan sentencias de la Corte a favor de la tribu yaqui ante la violación a su derecho territorial al agua sin pasar siquiera por el derecho a la consulta... (Gómez, 2015, párrs. 6-7).

\section{Conclusiones}

El multiculturalismo de corte liberal ayuda a explicar los retos y el significado de sociedades multiétnicas en un contexto amplio y global. En el caso mexicano, se precisa pasar de la explicación multicultural, a la práctica de un diálogo intercultural que consiga una convivencia pacífica en su sentido positivo. Dicha práctica intercultural tiene el potencial de transformar la práctica institucional en una que adopte un estado y un derecho plurales, que se correspondan con las realidades sociales de un Estado nación multiétnico y de enorme diversidad, como México.

El avance en la constitucionalización de los derechos fundamentales, y en especial de los derechos fundamentales de los pueblos indígenas en México mediante la incorporación de los pactos y convenciones internacionales, concretado en las reformas 
constitucionales de 2001 y 2011, sentaron las bases para un cambio en materia de la protección de los derechos humanos fundamentales de los pueblos indígenas de México, pero no han sido suficientes para garantizar el ejercicio pleno de sus derechos fundamentales a la autodeterminación, a la consulta previa libre e informada, o al disfrute de territorios y tierras ancestrales; ni los han protegido contra la extracción y el despojo de sus recursos naturales y los proyectos extractivos.

El derecho a la consulta previa, libre, informada, de buena fe y con el propósito de obtener el consentimiento, no es solo un derecho colectivo de los pueblos indígenas, sino también un deber de los Estados nación en términos de los estándares internacionales, y desde luego un deber exigible al Estado mexicano en su conjunto, pues está vinculado voluntariamente a los acuerdos, pactos, convenciones y mecanismos internacionales en la materia.

Los derechos fundamentales de los pueblos indígenas han sido desdeñados por las autoridades públicas en México, especialmente en el caso del estado de Sonora, al haberse realizado proyectos de infraestructura y extractivos sin consultarles, que afectan gravemente el modo de vida y amenazan la propia existencia de la tribu yaqui como pueblo diferenciado.

La lucha legal y pacífica de los yaquis emprendida en 2010 y cuyo caso llegó a la Suprema Corte de Justicia de la Nación en 2013, ha sentado un precedente muy importante en materia de derechos fundamentales de los pueblos indígenas, y en particular, sobre el derecho fundamental a la consulta.

El éxito de la lucha yaqui, sin embargo, no ha sido suficiente, pues las diferentes autoridades públicas han sido deliberadamente omisas con las sentencias que les ordenaron suspender las obras emprendidas y consultar a la tribu.

El caso expuesto demuestra que una sociedad nacional que es tan culturalmente diversa como la mexicana, reclama avanzar hacia la construcción de nuevos modelos de derecho, de justicia y de Estado que reconozcan y valoren plenamente el derecho a la diferencia. Esto implica sin duda proponer una concepción plural de la justicia y del derecho, si consideramos que puede haber tantos derechos como culturas diferentes existen, pues resulta que el Estado liberal está construido sobre el monismo jurídico, que tradicionalmente no ha reconocido el derecho a existir del otro, del diferente, o para ser más preciso: del "indio", en una tradición que viene de antiguo, donde ya el propio paralelismo jurídico virreinal que imperó en Nueva España durante casi 300 años, separaba a los "indios" y a los "criollos" o "peninsulares" en "repúblicas" distintas (Cossío, 2000).

Los pueblos indígenas de México son sujetos colectivos y titulares de derechos fundamentales plenamente reconocidos por el orden jurídico interno e internacional, aunque no por la práctica institucional mexicana. Dicha minoría vive y sobrevive dentro de estructuras estatales que tienden, en el mejor de los casos, a la pretensión de integrarlos o asimilarlos. La región noroeste de México no es la excepción a estos dilemas que plantea la multiculturalidad. Urge entonces reflexionar sobre los derechos de los pueblos indígenas tanto en su dimensión individual como colectiva; en la relación entre ellos y con la sociedad mestiza mayoritaria y en el significado normativo de una sociedad autodeclarada normativamente como plurinacional, dadas las múltiples implicaciones institucionales y sociales de dicho reconocimiento para el derecho y las leyes de un sistema jurídico dado.

A la luz del incumplimiento normativo y de la criminalización del movimiento social, la lucha indígena ha dejado de ser la lucha por una vuelta a un pasado "étnico y virginal" (Wallerstein, 2015), para ubicarse en la construcción y la reconstrucción de la 
democracia comunitaria y del pluralismo jurídico, y también para ser un movimiento político, politizado y nacional (es relevante el caso del Congreso Nacional Indígena CNI, y su Concejo de Gobierno, del cual forma parte la tribu yaqui, eligiendo precandidata a la Presidencia de la República y haciendo campaña por todo el país al final de 2017 y principios de 2018). En la movilización indígena, la aspiración a la autonomía es esencial, pues es la manera en la que los pueblos indígenas accederán a una de las demandas generalizadas de la ciudadanía en México: una democracia sustancial y no formal. De ahí la importancia de la vinculación del ideario indígena con las nuevas y viejas luchas de los movimientos sociales en México y en el resto del mundo, lo mismo que el cumplimiento efectivo y la justiciabilidad de sus derechos fundamentales.

Las luchas emancipadoras y los movimientos sociales iberoamericanos en los diferentes Estados nación, han ido empujando al pluralismo jurídico desde el constitucionalismo más o menos multicultural hasta llegar al constitucionalismo plurinacional, donde destacan señaladamente los casos de Bolivia y Ecuador (Yrigoyen, 2011). En este contexto, los reclamos de los grupos indígenas en pos de mantener sus patrones culturales y sus valores colectivos son de distinto tono. Y así surgen algunos dilemas como los siguientes: ¿Somos capaces de emprender políticas públicas para el desarrollo que introduzcan derechos diferenciados en cada caso? ¿Podemos respaldar un inevitable multiculturalismo que sea la base de la convivencia y el intercambio pacífico de valores culturales diferentes y que avance hacia la interculturalidad como política de Estado?

Más allá del tratamiento del tema en los diferentes contextos sociales, textos constitucionales y contenidos normativos, hace falta desentrañar una visión que articule elementos propios del derecho constitucional, del derecho internacional de los derechos humanos, de la sociología jurídica y también del derecho comparado para peguntarse: ¿debería entonces el Estado constitucional del siglo xxi, reconocer al pluralismo jurídico como un pilar de su configuración?; vale decir: ¿puede y debe reconocer el Estado nación la existencia de varios órdenes jurídicos que convivan en el espacio y tiempo en razón de diferentes necesidades culturales?

\section{Referencias}

Ackerman, J. M. (2016). El mito de la transición mexicana. México: Temas de Hoy.

Arango, J. (23 de marzo de 2002). ¿De qué hablamos cuando hablamos de multiculturalismo? El País. Recuperando de http:/ / elpais.com/diario/2002/03/23/ opinion/1016838006_850215.html

Bengoa, J. (2009) . ¿Una segunda etapa en la emergencia indígena en América Latina? Cuadernos de Antropología Social, (29), 7-22.

Bermejillo, E. (1997). Los pueblos indígenas y sus demandas. Alegatos, (36).

Calderón, F. J. (2009). El multiculturalismo revisitado. Sociedad Global, Revista de Relaciones Internacionales y Ciencias Políticas. Recuperado de www.eumed.net/rev/ $\mathrm{sg} / 03 / \mathrm{fjcv} \cdot \mathrm{htm}$

Carbonell, M. (2010). El Estado constitucional como herramienta para la calidad democrática. Recuperado de http/www.miguelcarbonell.com/artman/uploads/1/Calidad_de_la_democracia_y_Estado_de_Derecho.pdf. 
Casorla, F. (2010). Derecho y sociedad multicultural. Anuario de Derecho Penal. Recuperado de http://www.cervantesvirtual.com/obra/derecho-y-sociedad-multicultural/

Comisión Interamericana de Derechos Humanos (CIDH) y Organización de los Estados Americanos (oeA). (31 de diciembre de 2015). Situación de los derechos humanos en México (Informe de país México). Recuperado de http://www.oas. org/es/cidh/informes/pdfs/mexico2016-es.pdf

Corte Interamericana de Derechos Humanos (Corte IDH). (s.f.). Pueblos indígenas y tribales. Cuadernillo de Jurisprudencia de la Corte Interamericana de Derechos Humanos, (11). Recuperado de http://www.corteidh.or.cr/sitios/libros/todos/ docs/indigenas.pdf

Cortina, A. (22 de noviembre de 2005). Europa intercultural. El País. Recuperado de https://elpais.com/diario/2005/11/22/opinion/1132614008_850215.html

Cossío, D. (2000). Historia general de México. México: El Colegio de México.

Ferrajoli, L. (2004). Derechos y garantías. La ley del más débil. Madrid, España: Trotta.

Ferrajoli, L. (2006). Sobre los Derechos Fundamentales. Cuestiones Constitucionales, Revista Mexicana de Derecho Constitucional, (15), 113-136. Recuperado de http:// www.journals.unam.mx/index.php/cuc/article/view/2172/1734

Galtung, J. (1996). Peace by Peaceful Means: Peace and Conflict, Development and Civilization. Londres, Inglaterra: Sage.

García, A., Fuentes, N. A. y Montes, O. (2012). Desigualdad y polarización del ingreso en México: 1980-2008. Política y Cultura, (37), 285-310. Recuperado de http://www. scielo.org.mx/scielo.php?script=sci_arttext\&pid=S0188-77422012000100014\&l$\mathrm{ng}=\mathrm{es} \& \mathrm{tlng}=\mathrm{es}$

García, M. (2015). Chimalapas: La defensa del territorio y de los bienes naturales como factor de identidad indigena. Recuperado de https://www.iccaconsortium.org/wp-content/uploads/2016/04/example-Folleto-Chimalapas-2015-es.pdf

Gómez, J. L. (2002). Pueblos indígenas. Normas internacionales y marcos nacionales. Cuadernos Deusto de Derechos Humanos, (21).

Gómez, M. (24 de febrero de 2015). Los Acuerdos de San Andrés: 19 años. La Jornada. Recuperado de http://www.jornada.unam.mx/2015/02/24/opinion/020a1pol

Gutiérrez, R. (2018). El derecho fundamental al agua en México; un instrumento de protección para las personas y ecosistemas. Cuestiones Constitucionales. Revista Mexicana de Derecho Constitucional, (39). Recuperado de https://revistas.juridicas.unam.mx/index.php/cuestiones-constitucionales/article/view/5828/7705

Habermas, J. (1988). Facticidad y validez. Sobre el derecho y el Estado democrático de derecho en términos de teoría del discurso. Madrid, España: Trotta.

Habermas, J. (1999). La inclusión del otro. Estudios de teoría política. Barcelona, España: Paidós Ibérica.

Harvey, D. (2004). El "nuevo" imperialismo: Acumulación por desposesión. Buenos Aires, Argentina: Merlin Press, Clacso.

Instituto Nacional de Geografía y Estadística (Inegi). (5 de agosto de 2016). Estadísticas a propósito del día internacional de los pueblos indigenas (9 de agosto). Recuperado de http://www.inegi.org.mx/saladeprensa/aproposito/2016/indigenas2016_0.pdf 
Jiménez, A. (2006). Los vecinos españoles ante los indios de frontera: El Gran Norte de Nueva España. Brocar, Cuadernos de Investigación Histórica, (30). Recuperado de https://dialnet.unirioja.es/servlet/articulo?codigo $=2878408$

Jiménez, F. (2016). Paz intercultural. Europa, buscando su identidad. Revista de Paz y Conflictos, 9(1), 13-45.

Kymlicka, W. (1996). Ciudadanía multicultural. Una teoría liberal de los derechos de las minorías. Barcelona, España: Paidós.

Kymlicka, W. (2007). Las odiseas multiculturales. Las nuevas políticas internacionales de la diversidad. Barcelona, España: Paidós.

Lerma, E. (2014). Notas para el análisis de la resistencia yaqui en contra del Acueducto Independencia. Sociológica, 29(82), 255-271. Recuperado de http://www.scielo. org.mx/pdf/soc/v29n82/v29n82a8.pdf

López, F. (13 de septiembre de 2014a). El gobierno sonorense escala el enfrentamiento con la tribu yaqui. La Jornada. Recuperado de http://www.jornada.unam. $\mathrm{mx} / 2014 / 09 / 13 /$ opinion/018a1pol

López, F. (24 de septiembre de 2014b). El secuestro de Mario Luna. La Jornada. Recuperado de http://www.jornada.unam.mx/2014/09/24/opinion/025a1pol

López, F. (2015). ¡La tierra no se vende! Las tierras y los territorios de los pueblos indígenas de México. Recuperado de http://www.lopezbarcenas.org/files/escritos/La_tierra_no_se_vende_con_portada.pdf

Luna, M. (28 de febrero de 2017). El robo de un río en México [Mensaje en un blog]. Recuperado de https:/ /actualidad.rt.com/actualidad/232191-robo-rio-yaqui-mexico

Luna, M. (30 de enero de 2018). [Mensaje de redes sociales].

Luque, D., Martínez, A., Búrquez, A., Gómez E., Nava, A. y Rivera, M. (2012). Pueblos indígenas de Sonora: ¿el agua es de todos? Región y Sociedad, número especial (3). Recuperado de https://regionysociedad.colson.edu.mx:8086/index.php/ rys/article/view/408

Martínez, J. (2015). Ecología política del extractivismo y justicia socio-ambiental. Interdisciplina, 3(7), 57-73.

Martínez, J. L., Murillo, D. y Paré, L. (2017). Conflictos por el agua y alternativas en los territorios indígenas de México. México: Instituto Mexicano de Tecnología del Agua.

Martínez, P. (2008). Conquista, olvido, despojo, eje del exterminio de los pueblos indígenas en el Noroeste y Norte de México. Observatoire des Ameriques, Le Chronique des Ameriques, (18). Recuperado de http:/ /www.ieim.uqam.ca/IMG/pdf/ Chro-MARTINEZ-18-08.pdf

Meyer, L. (16 de octubre de 2014). Las naciones de nuestra nación. El Norte. Recuperado de http://www.elnorte.com/aplicacioneslibre/editoriales/editorial. aspx?id=38243\&md5=f5d4104cd839f01b3af86d12507c79aa\&ta=0dfdbac$11765226904 \mathrm{c} 16 \mathrm{cb} 9 \mathrm{ad1b2efe}$

Moreno, J. L. (2014). Despojo del agua en la cuenca del río Yaqui. México: El Colegio de Sonora.

Nájar, A. (31 de agosto de 2015). Yaquis: Los combatientes de la primera guerra del agua en México. Recuperado de http://www.bbc.com/mundo/noticias/2015/08/150828_ yaquis_mexico_guerra_agua_an 
Oficina en México del Alto Comisionado de Naciones Unidas para los Derechos $\mathrm{Hu}$ manos. (2018). Los derechos de los pueblos indígenas en México, una mirada desde el Sistema de Naciones Unidas. México: Autor.

Organización de las Naciones Unidas (ONU). (s.f.). Temas mundiales. Pueblos indígenas. Recuperado de http://www.un.org/es/globalissues/indigenous/

Padilla, R. (2011). Los irredentos parias, Los Yaquis, Madero y Pino Suarez en las elecciones de Yucatán en 1911. México: Instituto Nacional de Antropología e Historia.

Peritaje antropológico, impacto social y cultural por la operación del acueducto Independencia. (2015). Rutas de Campo.

Ramírez, E. (3 de junio de 2014). Sentencia de la Suprema Corte, "sin valor" para Conagua y gobierno sonorense. Contralínea. Recuperado de http://www.contralinea. com.mx/archivo-revista/2014/06/03/sentencia-de-la-suprema-corte-sin-valor-para-conagua-gobierno-sonorense/

Real Academia Española. (2016). Diccionario de la lengua española.

Santiago, R. (2010). El concepto de ciudadanía en el comunitarismo. Cuestiones Constitucionales, (23). Recuperado de http://www.scielo.org.mx/scielo.php?script=sci_arttext\&pid=S1405-91932010000200006

Santos, B. de S. (1998). Por una concepción multicultural de los derechos humanos, CEIH. México: Universidad Nacional Autónoma de México.

Sartori, G. (2001). La sociedad multiétnica. Pluralismo, multiculturalismo y extranjeros. Madrid, España: Taurus.

Shiva, V. (2004). Las guerras del agua: contaminación, privatización y negocio. Barcelona, España: Icaria.

Spicer, E. H. (1994). Los Yaquis: Historia de una cultura. México: Universidad Nacional Autónoma de México.

Stavenhagen, R. (1992). Los derechos indígenas: Algunos problemas conceptuales. Recuperado de http://www.corteidh.or.cr/tablas/R06852-4.pdf

Suprema Corte de Justicia de la Nación. (s.f.). Acueducto Independencia Yaquis. Amparo en Revisión, expediente 631/12. Recuperado de http://www.sitios.scjn.gob.mx/ codhap/completo/acueducto

Taibo II, F. I. (2014). Yaquis: Historia de una guerra popular y un genocidio en México. México: Planeta.

Taylor, C. (1993). El multiculturalismo y "la política del reconocimiento". México: Fondo de Cultura Económica.

The World Bank. (2015). Indigenous Latin American in the Twenty-First Century. Recuperado de http://documents.worldbank.org/curated/en/145891467991974540/ pdf/98544-REVISED-WP-P148348-Box394854B-PUBLIC-Indigenous-Latin-America.pdf

Toledo, V. M., Garrido, D. y Barrera-Bassols, N. (2015). The Struggle for Life: Socio-Environmental Conflicts in Mexico. Latin American Perspectives, 42(5). Recuperado de https://www.researchgate.net/publication/279169938_The_Struggle_for_Life

Torbisco, N. (2000). Minorías culturales y derechos colectivos: Un enfoque liberal (Tesis doctoral). Barcelona, España: Universitat Pompeu Fabra.

Turner, J. K. (1910). Barbarous Mexico. Recuperado de 132.248.9.34/ iih/001234242/001234242.pdf 
Wallerstein, I. (22 de febrero de 2015). El multiculturalismo y sus dilemas. La Jornada en Linea. Recuperado de http://www.jornada.unam.mx/2015/02/22/opinion/022a1mun

World Justice Project. (2018). Rule of Law Index, 2017-2018. Recuperado de https:// worldjusticeproject.org/sites/default/files/documents/WJP_ROLI_2017-18_ Online-Edition.pdf

Yrigoyen, R. (2011). El Horizonte del constitucionalismo pluralista: del multiculturalismo a la descolonización. En C. Rodríguez (Coord.). El derecho en América Latina: Un mapa para el pensamiento jurídico del siglo XxI. Buenos Aires, Argentina: Siglo XXI.

Zárate, J. L. (2016). Grupos étnicos de Sonora: Territorios y condiciones actuales de vida y rezago. Región y Sociedad, 28(65), 5-44.

\section{Material legislativo}

Constitución de la República Italiana. (1 de enero de 1948). Recuperado de http:// www.ces.es/TRESMED/docum/ita-cttn-esp.pdf

Constitución Política de los Estados Unidos Mexicanos. (14 de agosto de 2001). Diario Oficial de la Federación. Recuperado de https://www.juridicas.unam.mx/ legislacion/ordenamiento/constitucion-politica-de-los-estados-unidos-mexicanos\#10537

Constitución Política de los Estados Unidos Mexicanos. (10 de junio de 2011). Diario Oficial de la Federación. Recuperado de https://www.juridicas.unam.mx/ legislacion/ordenamiento/constitucion-politica-de-los-estados-unidos-mexicanos\#10537

Convención Americana sobre Derechos Humanos Suscrita en la Conferencia Especializada Interamericana sobre Derechos Humanos (B-32). Artículo 4º . (Noviembre de 1969). Recuperada de http://www.oas.org/dil/esp/tratados_B-32_Convencion_Americana_sobre_Derechos_Humanos.pdf

C169-Convenio sobre pueblos indígenas y tribales en países independientes, 1989. (1991). Recuperado de http://www.ilo.org/dyn/normlex/es/f?p=NORMLEXPUB:12100:0::NO::P12100_INSTRUMENT_ID:312314

Convenio Núm. 169 de la ort sobre pueblos indígenas y tribales. Declaración de las Naciones Unidas sobre los derechos de los pueblos indígenas. (2014). Recuperado de http://www.ilo.org/wcmsp5/groups/public/-americas/-ro-lima/ documents/publication/wcms_345065.pdf

Declaración de las Naciones Unidas sobre los derechos de los pueblos indígenas. (13 de septiembre de 2007). Recuperado de http://www.un.org/esa/socdev/unpfii/documents/DRIPS_es.pdf

Declaración de los Derechos del Hombre y del Ciudadano de 1789. (1789). Art. $1^{\circ}$. Recuperado de http://www.conseil-constitutionnel.fr/conseil-constitutionnel/ root/bank_mm/espagnol/es_ddhc.pdf

Estatuto de Roma de la Corte Penal Internacional. (2002). Recuperado de https:// www.icc-cpi.int/resource-library/documents/rs-esp.pdf 
Observación general $\mathrm{N}^{\circ}$ 15: El derecho al agua (artículos 11 y 12 del Pacto Internacional de Derechos Económicos, Sociales y Culturales). (s.f.). Recuperado de www.escr-net.org/es/recursos/observacion-general-no-15-derecho-al-agua-articulos-11-y-12-del-pacto-internacional

Pacto Internacional de Derechos Civiles y Políticos. (23 de marzo de 1976). Recuperado de http://www.ohchr.org/SP/ProfessionalInterest/Pages/CCPR.aspx

Enrique F. Pasillas

Mexicano. Doctorando en Ciencias Jurídicas en el Doctorado Iberoamericano en Estudios de Paz y Conflictos (Auip-ugr) de la Facultad de Derecho en el Instituto de la Paz y los Conflictos de la Universidad de Granada, España. Líneas de investigación: derechos fundamentales, derechos fundamentales de los pueblos indígenas, estudios de paz y conflictos. 